\title{
A INTERDISCIPLINARIDADE NO PROEJA: uma visão a partir dos trabalhos publicados em periódicos científicos nos últimos 10 anos
}

\author{
Fabrício Fernando Halberstadt 1 \\ Maria Cecillia Pereira Sant arosa ${ }^{2}$ \\ Isabel Krey Garcia ${ }^{3}$
}

\section{RESUMO}

O presente trabalho delineia os resultados de uma pesquisa bibliográfica, de cunho qualitativo que visou verificar como tem sido abordada a interdisciplinaridade, no âmbito do Programa Nacional de Integração da Educação Profissional com a Educação Básica na Modalidade de Educação de Jovens e Adultos (PROEJA), em artigos publicados em periódicos científicos, ao longo dos últimos dez anos. Foram analisados nove artigos os quais foram selecionados, a partir de busca realizada no Portal de Periódicos da Capes. A análise dos artigos foi realizada por meio da Análise Textual Discursiva (ATD), originando um metatexto, no qual se descrevem as três categorias finais que emergiram durante esse processo, a saber: Currículo integrado; Materiais didáticos e metodologias de ensino contextualizadas; Formação de professores. Por fim, verifica-se que a interdisciplinaridade é tratada nos trabalhos analisados, a partir do conceito de currículo integrado (integração entre formação humanística e profissional) e, para tanto, são necessários materiais e metodologias planejados de forma contextualizada, o que somente é possível por meio de uma formação docente permanente crítica.

Palavras-chave: Interdisciplinaridade. Programa Nacional de Integração da Educação Profissional com a Educação Básica na Modalidade de Educação de Jovens e Adultos. Pesquisa bibliográfica.

\footnotetext{
1 Doutorando do Programa Educação em Ciências: Química da Vida e Saúde da Universidade Federal de Santa Maria. Professor do Campus São Vicente do Sul do Instituto Federal de Educação, Ciêcia e Tecnologia Farroupilha. ORCID iD: https://orcid.org/00000001-7685-6954. E-mail: ffhalberstadt@gmail.com

${ }^{2}$ Doutora em Ensino de Física (Universidade Federal do Rio Grande do Sul). Professora do Programa Educação em Ciências: Química da Vida e Saúde da Universidade Federal de Santa Maria. ORCID iD: https://orcid.org/0000-0002-7656-9100. E-mail: mcpsrosa@smail.ufsm.br

${ }^{3}$ Doutora em Ensino de Física (Universidade Federal do Rio Grande do Sul). Professora do Programa Educação em Ciências: Química da Vida e Saúde da Universidade Federal de Santa Maria. ORCID iD: https://orcid.org/0000-0001-8080-6474. E-mail: ikrey69@gmail.com
} 


\title{
INTERDISCIPLINARITY IN THE PROEJA: a view from the works published in
}

\author{
scientific journals in the last 10 years
}

\begin{abstract}
The present work outlines the results of a qualitative bibliographical research aimed at verifying how the interdisciplinarity has been approached in the scope of the National Program of Integration of Professional Education with Basic Education in the Mode of Young and Adults Education (PROEJA) in published articles in scientific journals during the last ten years. Nine articles were analyzed, which were selected based on the search carried out in the Portal of Periodicals of Capes. The analysis of the articles was carried out through the Discursive Textual Analysis (DAT), originating a metatext in which the three final categories that emerged during this process were analyzed, namely: Integrated curriculum; Teaching materials and contextualized teaching methodologies; Teacher training. Finally, it is verified that interdisciplinarity is treated in the works analyzed from the concept of integrated curriculum (integration between humanistic and professional formation) and, for this, are necessary materials and methodologies planned in a contextualized way, which it is possible only by a permanent critical teacher training.
\end{abstract}

Keywords: Interdisciplinarity. National Program of Integration of Professional Education with Basic Education in the Mode of Young and Adults Education. Bibliographic research.

\section{LA INTERDISCIPLINARIEDAD EN EL PROEJA: un panorama de los trabajos publicados en periódicos científicos en los últimos 10 años}

\section{RESUMEN}

El presente trabajo enuncia los resultados de una investigación bibliográfica cualitativ a que tienen como propósito verificar cómola interdisciplinariedad ha sido abordada en el ámbito del Programa Nacional de Integración de la Educación Profesional con la Educación Básica en la modalidad de Educación de Jóvenes y Adultos (PROEJA), en artículos publicados en periódicos científicos a lo largo de los últimos diez años. Así, han sido analizados nueve artículos, los cuales han sido seleccionados a partir de búsquedas realizadas en el Portal de Periódicos Capes. El análisis de los artículos ha sido realizada por medio delAnálisis Textual Discursivo (ATD), originando un metatexto en lo cual han sido analizadas las tres categorías finales que surgirán durante ese proceso, las cuales fueron: currículo integrado; materiales didácticos y métodos de enseñanza contextualizadas; formación de docentes. Finalmente, ha sido verificado que la interdisciplinariedad es abordada en los trabajos analizados a partir del concepto de currículo integrado (integración entre formación humana y profesional) y, por lo tanto, son necesarios materiales y metodologías planificadas de forma contextualizada, lo que solamente es posible por medio de una formación docente permanentemente crítica.

Palabras clave: Interdisciplinariedad. Programa Nacional de Integración de la educación Profesional con la Educación Básica en la modalidad de Educación de Jóvenes y Adultos. Investigación bibliográfica. 


\title{
INTRODUÇÃO: CARACTERIZAÇÃO DA PESQUISA E DO PROEJA
}

No ano de 2017, completaram-se 10 anos da criação do PROEJA. Esse programa é ofertado, em geral, pela Rede Federal de Educação Profissional Científica e tem por finalidade, o desenvolvimento de cursos e programas de formação profissional inicial e continuada, nas formas integrada e concomitante, na modalidade de Educação de Jovens e Adultos (EJA). 0 programa é originário do Decreto $n^{\circ} .5 .478^{4}$, de 24/06/2005, e denominado inicialmente como Programa de Integração da Educação Profissional ao Ensino Médio, na Modalidade Educação de Jovens e Adultos. O PROEJA, tal como conhecemos hoje, foi instituído pelo decreto presidencial $N^{0} 5.8405$, de 13 de julho de 2006. O público-alvo do programa são jovens e adultos que possuem idade igual ou superior a 18 anos e que não tiveram a oportunidade de cursar o Ensino Fundamental e ou Ensino Médio, e que também buscam uma profissionalização técnica. Em 2007 foram publicados documentos oficiais que marcaram, de fato, o surgimento dos cursos do programa e que estabelecem as bases do PROEJA (BRASIL, 2007). Logo na apresentação do documento, encontra-se uma descrição que sintetiza as características e desafios do programa.

\begin{abstract}
O PROEJA é, pois, uma proposta constituída na confluência de ações complexas. Desafios políticos e pedagógicos estão postos e o sucesso dos arranjos possíveis só materializar-se-á e alcançará legitimidade a partir da franca participação social e envolvimento das diferentes esferas e níveis de governo em um projeto que busque não apenas a inclusão nessa sociedade desigual, mas a construção de uma nova sociedade fundada na igualdade política, econômica e social; em um projeto de nação que vise uma escola vinculada ao mundo do trabalho numa perspectiva radicalmente democrática e de justiça social (BRASIL, 2007, p. 8).
\end{abstract}

Pode-se observar uma preocupação especial (pelo menos em teoria), em auxiliar na construção de ideais democráticas, a partir de uma educação pautada no mundo do trabalho. Isso não reduz a função do

4 Disponível em < http://www.planalto.gov.br/ccivil_03/_ato2004-2006/2005/decreto/ d5478.htm> Acesso em: 2 out. 2017.

5 Disponível em <http://www.planalto.gov.br/ccivil_03/_ato2004-2006/2006/decreto/ D5840.htm> Acesso em: 2 out. 2017.

Revista Exitus, Santarém/PA, Vol. 9, № 3, p. 395 - 424, JUL/SET 2019. 
Estado à simples oferta de cursos profissionalizantes, mas sim, à formação de sujeitos críticos que possam transformar a sua própria realidade. O Documento Base do PROEJA (BRASIL, 2007) afirma que se trata de uma perspectiva de formação na vida e pela vida. Trata-se da formação humana (sentido lato), construção de conhecimentos científicos e tecnológicos bem como o acesso a uma profissionalização.

Dessa forma, é importante observar que a análise realizada em Brasil (2007) a respeito da situação da EJA no país, naquele momento (e que ainda se parece muito com a atual) é preocupante, devido ao número de jovens presentes nessa modalidade. Segundo o mesmo documento, estes jovens são o resultado do fracasso da Educação Básica desenvolvida na modalidade dita regular e que, ao defrontar-se com o mercado de trabalho, concluem que a negativa em postos de trabalho, deve-se, exclusivamente, a sua baixa escolarização. Assim, em Brasil (2007) conclui-se que a EJA tem público-alvo caracterizado, principalmente, por sujeitos marginais ao sistema, com atributos acentuados, de acordo com características como, por exemplo, de cor, raça/etnia, de gênero, entre outros. Trata-se de grupos sociais historicamente excluídos da sociedade, tais como: negros, quilombolas, desempregados, subempregados, mulheres, indígenas.

É a partir dessas constatações que o documento esclarece que o poder público, à época, não poderia mais omitir-se frente a essa situação (BRASIL, 2007). Seria necessário prover educação profissional de jovens e adultos. Porém, o PROEJA não poderia ser uma ação pontual, mas sim, uma política pública de institucionalização, de integração da educação profissional com a educação básica, na modalidade EJA. No que concerne à formação humana, afirma que deve considerar o mundo do trabalho.

A formação humana aqui tratada impõe produzir um arcabouço reflexivo que não atrele mecanicamente educação-economia, mas que expresse uma política pública de educação profissional integrada com a educação básica para jovens e adultos como direito, em um projeto nacional de desenvolvimento soberano, frente aos desafios de inclusão social e da globalização econômica (BRASIL, 2007, p. 17). 
Frente a este desafio, o mesmo documento propõe a articulação da modalidade EJA com a formação profissionalizante de nível médio. Para tanto, acredita-se que a busca pela interdisciplinaridade nesses cursos, pode proporcionar a interação entre as diferentes disciplinas que compõem as suas estruturas curriculares, potencializando $\circ$ processo ensino $e$ aprendizagem.

Assim, cabe investigar os avanços e conquistas do programa ao longo desses últimos 10 anos, bem como os desafios para a sua consolidação enquanto política pública. No que concerne ao presente trabalho, serão apresentados os resultados da pesquisa bibliográfica, realizada em artigos publicados nos últimos dez anos, em periódicos científicos, os quais abordam a interdisciplinaridade no contexto do PROEJA.

Cabe, então, enunciar o problema de pesquisa aqui tratado: Como tem sido abordada a interdisciplinaridade no âmbito do PROEJA, em artigos publicados em periódicos científicos, ao longo dos últimos dez anos? O que se objetivou nessa pesquisa de cunho qualitativo foi, portanto, analisar e descrever concepções, vivências e relatos encontrados em periódicos científicos a respeito da interdisciplinaridade, em cursos desse programa. Dessa forma, sua realização justifica-se pela necessidade de analisar o que já se encontra nas produções existentes sobre a temática e, a partir disso, planejar e realizar possíveis investigações e ações.

\section{INTERDISCIPLINARIDADE}

Os desafios da educação brasileira são muitos. Entre os mais significativos e atuais, podem-se citar: a infraestrutura de escolas; políticas públicas; gestão escolar e formação de professores. Para Pombo (2008), um tema que perpassa estes desafios é a interdisciplinaridade, afinal, para uma proposta curricular nesta perspectiva, embora que ainda não se tenha uma definição única para o conceito de interdisciplinar, as discussões em seu torno apontam para a necessidade de se adotar práticas de ensino que privilegiem uma abordagem não isolada das disciplinas curriculares e ou áreas do conhecimento. 
Já em Japiassu (1976), tem-se a clareza dos problemas oriundos da superespecialização do conhecimento, ou seja, para o autor os denominados especialistas ou experts possuem muito conhecimento, porém, restrito a um espectro específico de aplicação e que não é suficiente para tratar dos problemas que acometem o mundo, bem como nas dificuldades que encontram em suas atividades profissionais.

Manifesta-se, assim, uma distância crescente entre a ordem das coisas e as possibilidades de pensamento e ação dos responsáveis políticos, assistidos por seus estados-maiores de experts de todos os tipos. Aqueles que governam o mundo parecem incapazes de compreender o mundo, apesar dos meios de conhecimento cada vez mais numerosos e dos meios de intervenção cada vez mais eficazes de que dispõem (JAPIASSU, 1976, p. 10).

O cenário atual não parece ser muito diferente daquele relatado por Japiassu (1976), afinal, assistimos a cada dia a, por exemplo, conflitos internacionais, ataques aos direitos do cidadão brasileiro, e uma educação brasileira que está longe de apresentar a qualidade desejada. No que se refere a esta última, apesar de alguns avanços conquistados democraticamente ao longo das últimas décadas no Brasil, tais como a universalização da Educação Básica, a ampliação da oferta do Ensino Superior e a expansão da rede federal de ensino, a improvisação de soluções recentemente adotadas, tais como reformas no Ensino Médiob e a falta de investimentos e cortes orçamentários governamentais, na área da Educação, poderão afetar gravemente a qualidade do ensino e aprendizagem no país. Nesse sentido, é que se torna urgente pensar e promover uma formação integral do aluno.

Esse mesmo autor diz também que o papel fundamental de uma atividade interdisciplinar, é lançar pontes para religar as áreas do saber outrora separadas e isoladas. Para Fazenda (1994, p. 21-22), a interdisciplinaridade busca estabelecer uma relação de "[...] reciprocidade, de multiutilidade que pressupõe uma atitude diferente a ser assumida frente

6 Definida pela Lei $N^{\circ} 13.415$, de 16 de fevereiro de 2017. Disponível em: http://www.planalto.gov.br/ccivil_03/_ato 2015-2018/2017/lei/L13415.htm 
ao problema do conhecimento, ou seja, é a substituição de uma concepção fragmentária para uma concepção unitária do ser humano". Acredita-se que a implementação de práticas interdisciplinares pode contribuir para a formação dos alunos, à medida que colabora para o desenvolvimento de uma visão mais ampla de mundo, dos problemas que o acometem, bem como para a sua formação, inclusive favorecendo o processo ensino e aprendizagem.

Na busca de uma conceitualização de interdisciplinaridade, torna-se indispensável delimitar, ao menos de forma breve, o que se entende por disciplinaridade, multidisciplinaridade, pluridisciplinaridade e transdisciplinaridade.

Para Japiassu (1976), a disciplinaridade corresponde à especialização científica do saber em disciplinas, ou seja, trata-se da ciência propriamente dita.

[...] "disciplinaridade" significa a exploração científica especializada de determinado domínio homogêneo de estudo, isto é, o conjunto sistemático e organizado de conhecimentos que apresentam características próprias nos planos de ensino, da formação, dos métodos e das matérias; esta exploração consiste em fazer surgir novos conhecimentos que se substituem aos antigos (JAPIASSU, 1976, p. 72).

Evidentemente, que não se trata de negar os avanços científicos e tecnológicos alcançados por meio da especialização do saber como, por exemplo, na matemática, resultados abstratos sobre a Teoria de Grupos. Pelo contrário, trata-se de discutir as possibilidades de potencializar o processo ensino e aprendizagem, por meio de uma visão mais ampla do conhecimento, uma visão interdisciplinar.

Um segundo termo que cabe caracterizar é o de multidisciplinaridade, o qual refere à justaposição de disciplinas. Nessa perspectiva, utilizam-se recursos de diferentes disciplinas, sem a necessidade de cooperação entre estas. Para Japiassu (1976, p. 73), "multidisciplinar consiste em estudar um objeto, sob diferentes ângulos, mas sem que tenha, necessariamente, havido 
um acordo prévio sobre os métodos a seguir ou sobre os conceitos a serem utilizados".

No caso da pluridisciplinaridade, conforme Japiassu (op. cit .) ocorrem algumas relações entre as disciplinas, com certa cooperação, mas sem nenhuma coordenação.

Dessa forma, a partir da intensidade das trocas entre os especialistas e pelo grau de integração, pode-se chegar a uma caracterização inicial da interdisciplinaridade. Enquanto os casos multi e pluridisciplinar ocorrem a partir da existência de dois ou mais especialistas, sem integração conceitual nem metodológica, a interdisciplinaridade requer superação das fronteiras da especialização do conhecimento, as fronteiras disciplinares. Dessa forma, a interdisciplinaridade implica diálogo, intercâmbios, cooperação, colaboração e interação entre disciplinas.

Podemos dizer que nos reconhecemos diante de um
empreendimento interdisciplinar todas as vezes que ele conseguir
incorporar os resultados de várias especialidades, que tomar de
empréstimo a outras disciplinas certos instrumentos e técnicas
metodológicos, fazendo uso dos esquemas conceituais e das
análises que se encontram nos diversos ramos do saber, a fim de
fazê-los integrarem e convergirem, depois de terem sido
comparados e julgados (JAPIASSU, 1976, p. 75).

Sobre a transdisciplinaridade, esse mesmo autor lembra que esta foi definida por Jean Piaget (1896 a 1980), ao buscar um nível máximo de interação entre as disciplinas. Nesse caso, para Piaget (1970) não haveria fronteiras entre as disciplinas, seria um sistema total, com objetivos de sistemas globais. Porém, para ambos os autores e não diferente do cenário atual, a transdisciplinaridade encontra-se em nível utópico, afinal, requer uma mudança muito profunda em relação a como a ciência se organiza.

De forma semelhante à ciência, no ensino, a interdisciplinaridade também é de interlocução de saberes e conhecimentos. As Diretrizes Curriculares Nacionais para Educação Básica (DCN) definem a interdisciplinaridade no Ensino Médio, como "abordagem teórico- 
metodológica com ênfase no trabalho de integração das diferentes áreas do conhecimento" (BRASIL, 2013, p. 184).

Para Fazenda (2002, p. 12), a "interdisciplinaridade pauta-se numa ação em movimento. Pode-se perceber esse movimento em sua natureza ambígua, tendo como pressuposto a metamorfose, a incerteza". As interações entre as disciplinas não são pré-estabelecidas, as relações necessitam ser construídas. Sentimentos como angústia e incerteza são, portanto, comuns na busca pelo interdisciplinar.

O trabalho interdisciplinar na educação impõe grandes desafios, mas também novas possibilidades.

\begin{abstract}
A possibilidade de um trabalho de natureza interdisciplinar nas pesquisas sobre sala de aula anuncia-nos possibilidades que antes não eram oferecidas. Quando isso acontece, surge a oportunidade de revitalizar as instituições e as pessoas que nelas trabalham. $O$ processo interdisciplinar desempenha papel decisivo para dar corpo ao sonho de fundar uma obra de educação à luz da sabedoria, da coragem e da humildade (FAZENDA, 2002, p. 17-18).
\end{abstract}

Nessa perspectiva, Fazenda (op. cit.) aponta que a escolha pela interdisciplinaridade em sala de aula e ou pesquisa, necessita imaginação, planejamento. Porém, não é possível prever a intensidade das relações e resultados. E, portanto, para a autora, apresenta característica ambígua entre a força das transformações e momentos de recolhimento, espera e incerteza.

\title{
PERCURSOS METODOLÓGICOS E RESULTADOS ENCONTRADOS
}

A presente pesquisa pode ser classificada como qualitativa, pois sua principal característica reside na interpretação do pesquisador sobre os dados e informações coletadas (MOREIRA, 2003). Dessa forma, pretendeu-se descrever exaustivamente e, detalhadamente, indícios em busca de uma resposta ao problema de pesquisa.

Com base em Gil (2002), no que se refere aos procedimentos técnicos adotados, pode-se classificar a pesquisa como bibliográfica, haja vista que foi desenvolvida com base em material já elaborado, no caso artigos 
científicos. No que se refere aos seus objetivos, conforme o mesmo autor pode-se classificar a pesquisa como exploratória e descritiva. A exploração no presente trabalho reside na descoberta dos trabalhos científicos que abordam a interdisciplinaridade no PROEJA. A descrição concentrou-se nas características encontradas nos trabalhos analisados. Nesse sentido, o caráter descritivo da presente pesquisa, consiste na elaboração de um metatexto, a partir da metodologia da Análise Textual Discursiva (ATD) realizada a partir do corpus constituído pelos trabalhos encontrados na fase exploratória.

Antes de tudo, cabe esclarecer que a busca por artigos publicados em periódicos científicos, se deu por meio do Portal de Periódicos da Coordenação de Aperfeiçoamento de Pessoal de Nível Superior (Capes) ${ }^{7}$. A partir da busca por uma combinação de palavras-chave8, foram encontrados 29 resultados, com delimitação de publicação aos dez últimos anos, conforme justificado devido ao tempo de criação do PROEJA. Como requisito de qualidade das publicações encontradas, aplicou-se o filtro disponível no Portal selecionando-se apenas os revisados por pares, isto é, para sua publicação foi exigida a aprovação por pareceristas especialistas. A partir dessa restrição, obteve-se 23 trabalhos revisados por pares, os quais foram lidos com o intuito de verificar se, efetivamente, abordavam a interdisciplinaridade, no âmbito do PROEJA. A partir dessa leitura, selecionouse 9 artigos, pois os demais apenas citavam o PROEJA e a interdisciplinaridade, sem abordar estes temas ao longo do trabalho desenvolvido.

A seguir, apresenta-se $\circ$ Quadro 1 que contempla os 9 trabalhos analisados, bem como a temática abordada por cada.

\footnotetext{
7 Disponível em: http://www.periodicos.capes.gov.br/.

8 A busca pelos artigos foi realizada em 29 de outubro de 2017 utilizando as seguintes combinações de palavras-chave: (interdisciplinar* AND "proeja") OR (interdisciplinar* AND "Programa Nacional de Integração da Educação Profissional com a Educação Básica na Modalidade de Educação de Jovens e Adultos") OR (interdisciplinar* AND "National Program for the Integration of Professional Education with Basic Education in the Modality of Education of Youths and Adults").
} 
QUADRO 1 - Publicações analisadas

\begin{tabular}{|c|c|c|c|c|}
\hline Ano & Título & $\begin{array}{c}\text { Revista - Instituição } \\
\text { mantenedora da } \\
\text { revista }\end{array}$ & Autor (es) / Instituição & $\begin{array}{c}\text { Sobre o que trata o artigo? Como a interdisciplinaridade está } \\
\text { contida no texto? }\end{array}$ \\
\hline 2009 & $\begin{array}{l}\text { Formação de } \\
\text { leitores: o ensino } \\
\text { de Língua } \\
\text { Portuguesa em } \\
\text { turmas de EJA }\end{array}$ & $\begin{array}{l}\text { Revista HOLOS - } \\
\text { Instituto Federal do } \\
\text { Rio Grande do } \\
\text { Norte (IFRN) }\end{array}$ & $\begin{array}{l}\text { llane Ferreira Cavalcante } \\
\qquad \text { (IFRN) } \\
\text { Dhierclay de S. } \\
\text { Alcântara (IFRN) }\end{array}$ & $\begin{array}{l}\text { Reflexão sobre os resultados tabulados a partir de um questionário } \\
\text { aplicado entre alunos de duas turmas PROEJA, observando seus } \\
\text { perfis de leitor e identificando suas principais necessidades no } \\
\text { âmbito da leitura e da escrita. O projeto relatado no texto está } \\
\text { inserido em um grupo de pesquisa que visa pensar o ensino de } \\
\text { Língua Portuguesa, sob um ponto de vista interdisciplinar, no campus } \\
\text { Natal do Instituto Federal de Educação, Ciência e Tecnologia do Rio } \\
\text { Grande do Norte (IFRN). }\end{array}$ \\
\hline 2010 & $\begin{array}{l}\text { Percepção } \\
\text { ambiental dos } \\
\text { estudantes do } \\
\text { curso Técnico em } \\
\text { Alimentos do } \\
\text { PROEJA no IFRN - } \\
\text { campus Currais } \\
\text { Novos }\end{array}$ & $\begin{array}{l}\text { Revista HOLOS - } \\
\text { Instituto Federal do } \\
\text { Rio Grande do } \\
\text { Norte (IFRN) }\end{array}$ & $\begin{array}{l}\text { Luciana de C. Medeiros } \\
\text { (IFRN) } \\
\text { Wyllys Abel F. Tabosa } \\
\text { (UFRN) }\end{array}$ & $\begin{array}{l}\text { O estudo pretendeu avaliar a percepção ambiental dos estudantes } \\
\text { matriculados em uma turma do PROEJA técnico em alimentos do } \\
\text { IFRN - Campus Currais Novos, a fim de analisar a formação deles } \\
\text { como profissionais-cidadãos comprometidos com o meio ambiente. } \\
\text { A interdisciplinaridade surge no texto a partir da menção aos PCNs, } \\
\text { os quais abordam a operacionalização da educação ambiental em } \\
\text { sala de aula de forma interdisciplinar e, além disso, conclui que o } \\
\text { tema não é trabalhado na perspectiva interdisciplinar no referido } \\
\text { curso. }\end{array}$ \\
\hline 2011 & $\begin{array}{l}\text { Experiências de } \\
\text { ensino no } \\
\text { PROEJA: práticas } \\
\text { de leitura e } \\
\text { escrita que vão } \\
\text { do Cordel à } \\
\text { Filosofia }\end{array}$ & $\begin{array}{l}\text { Revista HOLOS - } \\
\text { Instituto Federal do } \\
\text { Rio Grande do } \\
\text { Norte (IFRN) }\end{array}$ & $\begin{array}{l}\text { Lucrécio A. de Sá Júnior } \\
\text { (UFRN) } \\
\text { José Milson Santos (IFRN) }\end{array}$ & $\begin{array}{l}\text { Trata-se de um relato de uma experiência interdisciplinar, o qual } \\
\text { versou sobre a elaboração de folhetos de cordel, a partir da leitura } \\
\text { de textos filosóficos. A atividade envolveu as disciplinas de Filosofia, } \\
\text { Português e Literatura de um curso PROEJA técnico em Informática } \\
\text { do Campus João Câmara do IFRN. }\end{array}$ \\
\hline 2012 & $\begin{array}{l}\text { PROEJA: entre } \\
\text { desafios e } \\
\text { possibilidades }\end{array}$ & $\begin{array}{l}\text { Revista HOLOS - } \\
\text { Instituto Federal do } \\
\text { Rio Grande do } \\
\text { Norte (IFRN) }\end{array}$ & $\begin{array}{l}\text { Dante Henrique Moura } \\
\text { (IFRN) } \\
\text { Ana Lúcia S. Henrique } \\
\text { (IFRN) }\end{array}$ & $\begin{array}{l}\text { Os autores buscam no artigo caracterizar por meio de revisão } \\
\text { bibliográfica e análise de documentos o PROEJA, enfocando os } \\
\text { equívocos em sua implantação, suas possibilidades e desafios. Uma } \\
\text { das ações abordadas pelo autor que foram realizadas para a } \\
\text { melhoria do PROEJA, foi a criação de cursos de especialização para } \\
\text { atuação docente no programa. Com base em documentos oficiais, } \\
\text { os autores apontam que uma das características que tais cursos } \\
\text { deveriam apresentar é a interdisciplinaridade. }\end{array}$ \\
\hline
\end{tabular}




\begin{tabular}{|c|c|c|c|c|}
\hline \multirow[t]{2}{*}{2013} & $\begin{array}{l}\text { Construindo um } \\
\text { modelo curricular } \\
\text { integrado para a } \\
\text { Educação de } \\
\text { Jovens e } \\
\text { Adultos/ } \\
\text { formação inicial e } \\
\text { continuada } \\
\text { (EJA/FIC) }\end{array}$ & $\begin{array}{c}\text { Revista HOLOS - } \\
\text { Instituto Federal do } \\
\text { Rio Grande do } \\
\text { Norte (IFRN) }\end{array}$ & $\begin{array}{l}\text { Raimundo Nonato O. } \\
\text { Furtado - (IFPB) } \\
\text { Mônica Maria M. de } \\
\text { Oliveira (IFPB) }\end{array}$ & $\begin{array}{l}\text { O artigo apresenta um modelo possível de desenvolvimento } \\
\text { estrutural curricular integral, composto a partir de uma experiência } \\
\text { dos autores com o Projeto Mulheres Mil realizado no Instituto Federal } \\
\text { de Educação, Ciência e Tecnologia da Paraíba (IFPB). A } \\
\text { interdisciplinaridade é apontada pelos autores como necessidade } \\
\text { de reconciliação epistemológica, de modo que serviu para conciliar } \\
\text { os conceitos pertencentes às diversas áreas do conhecimento } \\
\text { envolvidas. }\end{array}$ \\
\hline & $\begin{array}{l}\text { Interdisciplinarida } \\
\text { de no PROEJA: } \\
\text { uma proposta } \\
\text { possível no } \\
\text { caderno } \\
\text { temático Saúde e } \\
\text { Números } \\
\end{array}$ & $\begin{array}{l}\text { Revista BOLEMA - } \\
\text { Universidade } \\
\text { Estadual Paulista } \\
\text { Júlio de Mesquita } \\
\text { Filho (UNESP) - Rio } \\
\quad \text { Claro }\end{array}$ & $\begin{array}{l}\text { Paula Reis de Miranda } \\
\text { (UFMG) } \\
\text { Eliane Scheid Gazire } \\
\text { (PUC Minas) }\end{array}$ & $\begin{array}{l}\text { No artigo descreve-se um recorte da dissertação de uma das } \\
\text { autoras no qual é analisada a potencialidade de um material } \\
\text { produzido contendo possibilidades investigativas, manipulativas e } \\
\text { interdisciplinares de trabalho com a Matemática e a Química em } \\
\text { um curso PROEJA Técnico em Agente Comunitário de Saúde do } \\
\text { Instituto Federal do Sudeste de Minas - Campus Rio Pomba. }\end{array}$ \\
\hline 2014 & $\begin{array}{c}\text { O projeto } \\
\text { integrador e a } \\
\text { centralidade do } \\
\text { trabalho... }\end{array}$ & $\begin{array}{l}\text { Revista HOLOS - } \\
\text { Instituto Federal do } \\
\text { Rio Grande do } \\
\text { Norte (IFRN) }\end{array}$ & $\begin{array}{l}\text { Eliesér Toretta Zen (IFES) } \\
\text { Edna Castro Oliveira } \\
\text { (UFES) }\end{array}$ & $\begin{array}{l}\text { Os autores relatam uma investigação envolvendo } \\
\text { desenvolvimento e avaliação do Projeto Integrador com alunos do } \\
\text { PROEJA Técnico em Edificações do campus de Vitória/ES do Instituto } \\
\text { Federal do Espírito Santo (Ifes). O Projeto Integrador consiste em um } \\
\text { componente curricular o qual os autores abordaram de forma } \\
\text { interdisciplinar. }\end{array}$ \\
\hline 2015 & $\begin{array}{l}\text { La Formación } \\
\text { Docente y la } \\
\text { Educación de } \\
\text { Jóvenes y } \\
\text { Adultos... }\end{array}$ & $\begin{array}{l}\text { Revista Formación } \\
\text { Universitaria - } \\
\text { Centro de } \\
\text { Información } \\
\text { Tecnológica de La } \\
\text { Serena, Chile. }\end{array}$ & $\begin{array}{l}\text { Lorenna S. O Costa (IFG) } \\
\text { Victor F. A. Barros (Univ. } \\
\text { do Minho - Portugal) } \\
\text { Márcia C. R. Lopes (IFG) } \\
\text { Luciana P. Marques (IFG) }\end{array}$ & $\begin{array}{l}\text { O artigo discute e analisa o processo de elaboração e } \\
\text { implementação de um projeto realizado no PROEJA Técnico em } \\
\text { Informática do Instituto Federal de Goiás (IFG), que trata o ensino de } \\
\text { ciências na perspectiva interdisciplinar, a partir da discussão de } \\
\text { problemas sociais. Contou com a participação de professores } \\
\text { formadores e professores em formação inicial. }\end{array}$ \\
\hline 2016 & $\begin{array}{l}\text { O PROEJA no } \\
\text { IFRN-Campus } \\
\text { Mossoró por seus } \\
\text { estudantes }\end{array}$ & $\begin{array}{l}\text { Revista HOLOS - } \\
\text { Instituto Federal do } \\
\text { Rio Grande do } \\
\text { Norte (IFRN) }\end{array}$ & $\begin{array}{l}\text { Jose Moises Silva (IFRN) } \\
\text { Lanuzia Tércia Sá (IFRN) }\end{array}$ & $\begin{array}{l}\text { Objetivo dos autores é analisar, sob a perspectiva dos estudantes, } \\
\text { como o campus Mossoró do IFRN vem materializando a proposta } \\
\text { curricular do curso técnico integrado em Edificações oferecido no } \\
\text { âmbito do PROEJA. Os autores concluem que ações } \\
\text { interdisciplinares são realizadas apenas pontualmente no curso, não } \\
\text { sistematizadas nem planejadas coletivamente. }\end{array}$ \\
\hline
\end{tabular}


Pode-se observar que 7 dos 9 trabalhos analisados foram publicados na revista HOLOS, mantida pelo IFRN. Isso, provavelmente, é influenciado pelo número de cursos PROEJA que esta instituição oferta que, atualmente, é oito e, além disso, pelo engajamento pessoal nessa modalidade pelo corpo docente dessa instituição, que, inclusive, conta com o professor Dante Henrique Moura, um dos autores do Documento Base do PROEJA - Brasil (2007), e que tem outras publicações sobre o PROEJA, sendo atualmente um grande defensor e incentivador do programa.

Um fato importante de ser mencionado é que, dentre as publicações analisadas, apenas Miranda e Gazire (2013) citam referencial específico sobre o que é a interdisciplinaridade. Nesse sentido, acredita-se que, apesar de ser crescente a demanda pela interdisciplinaridade na educação brasileira, ainda faz-se necessária a discussão teórica em relação a este conceito, afinal, pode colaborar para a sua compreensão, bem como incentivar e viabilizar práticas interdisciplinares no âmbito do PROEJA.

A análise dos 9 trabalhos selecionados foi realizada por meio da metodologia da Análise Textual Discursiva (ATD). Segundo Moraes (2003, p. 192) a ATD pode ser compreendida como

[...] um processo auto-organizado de construção de compreensão em que novos entendimentos emergem de uma sequência recursiva de três componentes: desconstrução dos textos do corpus, a unitarização; estabelecimento de relações entre os elementos unitários, a categorização; o captar do novo emergente em que a nova compreensão é comunicada e validada.

No caso presente, o corpus é constituído pelos 9 trabalhos selecionados. A unitarização foi realizada a partir da desconstrução de trechos dos artigos (ao todo foram destacadas 143 unidades entre palavras, frases e parágrafos). Em seguida, procedeu-se à categorização. Foram definidas 9 categorias iniciais, 5 intermediárias e 3 finais, as quais são apresentadas a seguir. 
QUADRO 2 - Categorias iniciais, intermediárias e finais

\begin{tabular}{|c|c|c|}
\hline Categorias iniciais & Categorias intermediárias & Categorias finais \\
\hline Fragmentação do saber & \multirow{3}{*}{ Currículo integrado } & \multirow{3}{*}{ Currículo integrado } \\
\hline Formação integral & & \\
\hline Problemas complexos & & \\
\hline Materiais e Métodos & \multirow{2}{*}{$\begin{array}{c}\text { Materiais e metodologias } \\
\text { adequados à realidade do aluno }\end{array}$} & \multirow{5}{*}{$\begin{array}{l}\text { Materiais didáticos e } \\
\text { metodologias de ensino } \\
\text { contextualizadas }\end{array}$} \\
\hline Realidade e Cotidiano & & \\
\hline Contextualização & \multirow{2}{*}{$\begin{array}{l}\text { Contextualizar potencializa a } \\
\text { interação }\end{array}$} & \\
\hline Interação & & \\
\hline Abordagem temática & Abordagem temática & \\
\hline Formação de Professores & Formação de Professores & Formação de Professores \\
\hline
\end{tabular}

Fonte: os autores - baseado em Moraes (2003).

A seguir, a imagem ilustra o processo de categorização, onde, da esquerda para a direita: categorias iniciais, categorias intermediárias, categorias finais.

FIGURA 1 - Categorias obtidas a partir da ATD
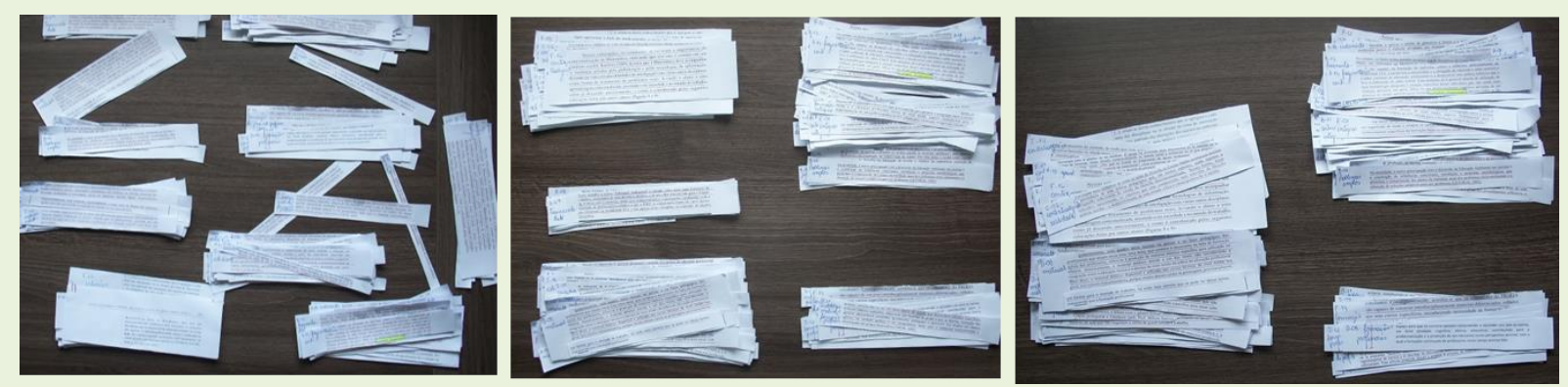

Fonte: os autores - baseado em Moraes (2003)

A partir desse processo, construiu-se o metatexto apresentado a seguir que procura comunicar e validar o novo emergente, a interpretação dos autores sobre o fenômeno estudado, a partir da descrição de cada categoria final: currículo integrado, materiais didáticos e metodologias de ensino contextualizadas e formação de professores. 


\section{Currículo integrado}

A perspectiva interdisciplinar surge nos trabalhos analisados, a partir do conceito de currículo integrado, sobre o qual está edificada a ideia de Educação Profissional Técnica no Brasil. Trata-se de integrar o mundo de trabalho e a educação, conforme se pode observar em unidades destacadas a seguir de textos analisados.

É neste ponto que reside o sentido de integração entre o mundo do trabalho e a educação: a constatação da identidade entre as capacidades demandadas pelo exercício da cidadania e pela atividade produtiva, o que permitiria construir um currículo do Proeja em que se pudesse superar a dicotomia entre a racionalidade técnica e o caráter abstrato dos ideais de formação humana (ZEN; OLIVEIRA, 2014, p. 136).

Até porque o sentido de um currículo integrado é bem mais amplo do que o mero reunir, em um mesmo currículo, processos educativos com finalidades próprias (ensino médio e educação profissional). Implica considerar uma formação em que os dois tipos de conhecimentos (formação geral e formação profissional) estejam imbricados desde o início do curso, de modo que os aspectos científico-tecnológicos, humanísticos e culturais estejam integrados e contemplados de forma equânime (SILVA; SÁ, 2016, p. 382).

A discussão em torno do currículo integrado se intensificou, a partir da publicação do Decreto-lei $n^{\circ}$ 5.154/20049, o qual instituiu, entre outras providências, a articulação entre a educação profissional técnica, de nível médio e o ensino médio, na modalidade integrada. Porém, como o próprio nome indica, a integração não é sinônimo de justaposição. Ou seja, ao contrário do que é, por vezes, relatado e presenciado, a integração vai muito além da simples oferta simultânea de disciplinas vinculadas às áreas básicas (Linguagens, Ciências da Natureza, Matemática e Ciências Humanas) e de disciplinas de uma área técnica, a qual caracteriza a formação profissional do curso.

Pode-se observar que tais cursos preconizam lao menos no plano teórico) uma educação voltada para a formação humana integral. Na resolução n 6, de 20 de setembro de 2012 da Câmara de Educação Básica,

\footnotetext{
9 Disponível em: <http://www.planalto.gov.br/ccivil_03/_ato2004-2006/2004/decreto/d5154. htm> Acesso em: 29 out. 2017.
} 
Brasil (2012), que define Diretrizes Curriculares Nacionais para a Educação Profissional Técnica de Nível Médio, estão apontados, entre outros, como princípios norteadores:

I - relação e articulação entre a formação desenvolvida no Ensino Médio e a preparação para o exercício das profissões técnicas, visando à formação integral do estudante;

III - trabalho assumido como princípio educativo, tendo sua integração com a ciência, a tecnologia e a cultura como base da proposta político-pedagógica e do desenvolvimento curricular; (BRASIL, 2012, p. 2).

Nesse sentido, não é possível pensar o desenvolvimento de um curso PROEJA quando desenvolvido de forma segmentada, estritamente disciplinar. O Documento Base do Proeja, Brasil (2007, p. 13), estabelece que "a perspectiva precisa ser, portanto, de formação na vida e para a vida e não apenas, de qualificação do mercado ou para ele". Busca-se a formação de um cidadão, que seja capaz de refletir sobre o mundo e modificá-lo, à medida que participa dos processos sociais. Em especial, no que se refere ao PROEJA, Moura e Henrique (2012) apontam que um dos grandes desafios do programa é integrar o ensino médio, a formação profissional técnica de nível médio e a Educação de Jovens e Adultos, campos historicamente distantes entre si.

\begin{abstract}
Igualmente desafiante é conseguir fazer com que as ofertas resultantes do Programa efetivamente contribuam para a melhoria das condições de participação social, política, cultural e no mundo do trabalho desses coletivos, em vez de produzir mais uma ação de contenção social. Coloca-se ainda outro desafio em um plano mais elevado: a transformação desse Programa em política educacional pública do estado brasileiro (MOURA; HENRIQUE, 2012, p. 116).
\end{abstract}

\begin{abstract}
A implantação do PROEJA na rede federal de Educação Profissional e Tecnológica fomentou a necessidade de investigar as possibilidades da construção de atividades experimentais e interdisciplinares para o curso de Agente Comunitário de Saúde, a fim de proporcionar ao estudante uma formação integral (MIRANDA; GAZIRE, 2013, p. 481).
\end{abstract}

Entende-se que a formação integral defendida pelos autores supõe uma ruptura com o modelo educacional vigente, por vezes marcado 
unicamente pelo tecnicismo. Nesse sentido, em Brasil (2007, p. 41) é destacado que é necessário pensar em "possibilidades de ver mais complexamente a realidade e, por esse ponto de vista, pensar também a intervenção pedagógica". Dessa forma, torna-se imperiosa uma abordagem interdisciplinar no PROEJA, ou seja, para tais problemas, uma abordagem disciplinar, marcada unicamente por superespecialistas não é suficiente (JAPIASSU, 1976).

Sem perspectiva de interlocutor e da percepção das condições de produção, as escritas realizadas no âmbito escolar se mostram "artificiais", sem objetivo, ineficientes na construção da subjetivação do sujeito. Em vista disso, o cordel como suporte para aulas de filosofia na Educação de Jovens e Adultos na experiência realizada se estabeleceu como um meio para aumentar, significativamente, a criatividade e a produção e compreensão de textos; portanto, ferramenta útil para transformar a percepção crítica dos alunos, condição indispensável para enfrentar complexos problemas de um mundo caracterizado por rápidas transformações, crescente complexidade e risco (SÁ JÚNIOR; SANTOS, 2011, p. 119).

Para Pombo (2005, p.11),

Perceber a transformação epistemológica em curso é perceber que lá, onde esperávamos encontrar o simples, está o complexo, o infinitamente complexo. Que quanto mais fina é a análise, maior a complexidade que se abre à nossa frente. E, portanto, que o todo não é a soma das partes.

De forma análoga, Giacon (2002, p. 38) lembra que "Complexus significa o que foi tecido junto". A autora afirma que são necessárias conexões entre os conhecimentos para que estes assumam significado e sentido. Pode-se perceber que esta ideia está presente nos textos analisados, à medida que para os autores, de uma forma geral, é imperioso buscar articular, relacionar, conectar conhecimentos de diferentes áreas do saber.

Deste modo, cabe a instituições de ensino promover a educação ambiental de maneira integrada aos programas educacionais que desenvolvem, articulando as questões ambientais locais, regionais, nacionais e globais, objetivando que os estudantes atinjam um nível esperado de percepção ambiental crítica, a fim de eles buscarem as soluções para as problemáticas ambientais, a fim de compreender o mundo que o envolve (MEDEIROS; TABOSA, 2010, p. 191). 
É um momento coletivo em que professores e alunos mediados pelo projeto integrador refletem sobre questões de natureza política, econômica, cultural, social, ética e ambiental, recriando o conhecimento para além da fragmentação das disciplinas escolares, tendo como premissa a concepção de conhecimento como totalidade social, favorecendo dessa forma, a formação integral do aluno do Proeja, na medida em que articula e integra no desenvolvimento do projeto, em todas as suas fases, a form ação geral e a formação técnica (ZEN; OLIVEIRA, 2014, p. 140).

Essa busca em conectar conhecimentos se dá em virtude da fragmentação do saber ocorrida, principalmente, devido à Revolução Industrial a partir do séc. XVIII e o surgimento do racionalismo técnico. Essa fragmentação é apontada, inclusive, como uma das principais responsáveis pelo fracasso escolar no PROEJA e nos demais níveis e modalidades de ensino.

No entanto, os dados acima também mostram que as disciplinas do Curso Técnico de Nível Médio em Alimentos na Modalidade EJA estão sendo trabalhadas sem perspectiva interdisciplinar. Deste modo percebe-se que os saberes das disciplinas estão sendo abordados, porém sem o olhar ambiental integrado ao conhecimento proposto em cada disciplina. Assim o conhecimento acerca das questões ambientais está fragmentado e acumulado apenas na disciplina de Gestão Ambiental, já no final do curso, no qual os alunos terão visto grande parte do conhecimento requerido para sua formação e poderão prejudicar sua compreensão mais globalizada dos problemas ambientais gerados pelas empresas de alimentos (MEDEIROS; TABOSA, 2010, p.193).

No caso do PROEJA, devido a sua natureza, a mais frequente desconexão entre conhecimentos ocorre entre a formação humanística e a profissionalização.

\begin{abstract}
A burguesia brasileira sempre negou a escolaridade básica e, como consequência, a formação profissional efetiva à maioria dos jovens e adultos trabalhadores. Em seu projeto sempre esteve uma educação unidimensional a serviço do mercado e do capital. Seu objetivo sempre consistiu na oferta de uma educação profissional descolada de uma formação de cultura geral estruturante da consciência ativa dos homens (ZEN; OLIVEIRA, 2014, 137).
\end{abstract}

No entanto, os trabalhos analisados apresentam, então, possibilidades e iniciativas que visam integrar diferentes áreas e ou disciplinas a fim de uma melhoria na formação dos alunos de cursos PROEJA. 
Espontaneamente, a interdisciplinaridade surge como uma resposta à necessidade de uma reconciliação epistemológica, processo necessário devido à fragmentação dos conhecimentos ocorridos com a revolução industrial e a necessidade de mão de obra especializada. A interdisciplinaridade serviu para conciliar os conceitos pertencentes às diversas áreas do conhecimento, a fim de promover avanços como a produção de novos conhecimentos na área de formação específica, no caso em tela, a pesca (FURTADO; OLIVEIRA, 2013, 247).

Por meio das duas últimas citações, pode-se observar que a busca em reconciliar os conhecimentos outrora fragmentados implica em investigar materiais e metodologias que possam potencializar $o$ ensino e aprendizagem.

\title{
Materiais didáticos e metodologias de ensino contextualizadas
}

Uma questão importante sobre a qual é necessário refletir é: quais conexões entre as áreas de conhecimento podem potencializar, de forma satisfatória, o processo de ensino e aprendizagem na perspectiva interdisciplinar? Uma resposta encontrada na análise dos artigos corresponde a considerar a realidade do aluno e, a partir disso, primar pela contextualização nesse processo.

Dadas às peculiaridades de cursos PROEJA não se pode reproduzir um ensino tradicional, muitas vezes pautado unicamente na utilização do livro didático.

\begin{abstract}
Historicamente, o material didático atende a um dos níveis, não considerando a integração entre a educação básica e o técnico de nível médio da esfera da educação profissional. Além disso, o material didático disponível e utilizado nos cursos técnicos de nível médio, em geral, tem talante instrumentalista, porque muitos desses cursos se preocupam, prioritariamente, em formar para o mercado de trabalho, na visão mais estreita que se pode ter desse termo (MOURA; HENRIQUE, 2012, p. 121-122).
\end{abstract}

A busca por materiais adequados está imbricada com a necessidade de se rever as metodologias adotadas no PROEJA.

Algunos estudios revelan que los principales problemas en la educación de jóvenes y adultos son la falta de adecuación del currículo y la ausencia de una propuesta de intervención 
pedagógica que satisfaga las necesidades de este público (Costa, 2010). Por otro lado, no hay muchos profesionales dispuestos a pensar en un proyecto que tenga en cuenta las especificidades de esta modalidad educacional (COSTA, et al, 2015, p. 4).

Por isso, a materialização do currículo integrado no curso de Edificações exige práticas pedagógicas pensadas coletivamente, de modo a proporcionar ao estudante a compreensão dos fundamentos científicos e tecnológicos que permeiam a área de construção civil e as relações econômicas, políticas, sociais e culturais presentes nas sociedades (SILVA; SÁ, 2016, p. 382).

Pode-se verificar que a discussão em torno das metodologias a serem utilizadas no PROEJA estão também relacionadas com os conteúdos a serem desenvolvidos no âmbito de cada curso do programa.

Foi programado para possibilitar o desenvolvimento de ferramentas, técnicas e currículos que permitissem o acesso, capacitação e assistência a mil mulheres, no mínimo, dispondo-lhes formação profissional e tecnológica, cursos de cidadania, inclusão digital, cooperativismo, empreendedorismo, meio ambiente, sustentabilidade e saúde, além de direitos das mulheres, tendo como alvo sua inserção no mercado de trabalho ou sua especialização (FURTADO; OLIVEIRA, 2013, p. 238).

Verifica-se ao longo da análise, que para os autores, os conteúdos devem ser trabalhados de forma interdisciplinar e que devem ser selecionados, considerando-se a pertinência destes para a formação integral do aluno e a realidade na qual está inserido. As experiências e vivências dos alunos podem ser propulsoras para a construção de conhecimentos científicos relevantes.

\begin{abstract}
Pensar a própria identidade é uma forma de fazer o aluno assumir a responsabilidade sobre sua própria formação e, dessa forma, envolver-se mais ativamente no processo de ensino-aprendizagem. A exploração das diferentes linguagens humanas, a escrita sobre aspectos pontuais de seu passado e de sua formação, a projeção de desejos para o seu futuro são atividades importantes nesse processo. Mas não podem fugir ao fato de que, para atingir realmente o aluno, precisam estar fundamentadas naquilo que eles apresentam de saberes prévios e perspectivas diante da escola (CAVALCANTE; ALCÂNTARA, 2009, p. 138-139).
\end{abstract}

Buscar ensinar, a partir das vivências, dos saberes prévios dos alunos, possibilita uma diminuição na fragmentação dos conteúdos à medida que incentiva o diálogo entre as disciplinas (COSTA et al, 2015). É a partir dessas 
considerações que a contextualização é recurso apontado nos textos explícita e implicitamente. Mas, o que vem a ser a contextualização?

A ideia de contextualização está fortemente relacionada com a interdisciplinaridade. Os Parâmetros Curriculares Nacionais para O Ensino Médio, afirmam que:

\begin{abstract}
A aprendizagem significativa pressupõe a existência de um referencial que permita aos alunos identificar e se identificar com as questões propostas. Essa postura não implica permanecer apenas no nível de conhecimento que é dado pelo contexto mais imediato, nem muito menos pelo senso comum, mas visa a gerar a capacidade de compreender e intervir na realidade, numa perspectiva autônoma e desalienante. Ao propor uma nova forma de organizar o currículo, trabalhado na perspectiva interdisciplinar e contextualizada, parte-se do pressuposto de que toda aprendizagem significativa implica uma relação sujeito-objeto e que, para que esta se concretize, é necessário oferecer as condições para que os dois polos do processo interajam (BRASIL, 2000, p. 22).
\end{abstract}

Dessa forma, é preciso considerar a realidade do aluno, problematizála. Conforme lembram as Diretrizes Curriculares Nacionais para a Educação Profissional Técnica de Nível Médio, trata-se de superar a visão de que, primeiramente, se ensina algo no plano teórico para que, então, depois o educando faça a sua aplicação.

As instituições internacionais de Educação Profissional nos têm ensinado que a melhor maneira para desenvolver os saberes profissionais dos trabalhadores está na sua inserção nas várias dimensões da cultura, da ciência, da tecnologia e do trabalho, bem como de sua contextualização, situando os objetivos de aprendizagem em ambiente real de trabalho (BRASIL, 2012, p. 11).

É essa a concepção presente nos trabalhos analisados, como é evidenciado nas citações a seguir.

El grupo ha analizado esas discusiones en la realidad de la ciudad de Inhumas, Goiás (Brasil), contextualizando un debate social y ambiental en el que emergieron algunas preguntas, como: ¿̇Por qué no invertir en tratamiento de aguas residuales? ¿Qué problemas ambientales se derivan de la ausencia de tratamiento? ¿Qué problemas de salud puede tener o ya tiene la población? (COSTA, et al, 2015, p.8). 
Nessas colocações, os estudantes destacaram a importância da contextualização da Matemática, indicando que isso não é comum em seu cotidiano escolar. Kuenzer (2005) 10 destaca que a Matemática deve acompanhar as mudanças geradas pela globalização e pelas tecnologias de informação, devendo ser vista com possibilidades de interligação com várias outras disciplinas, como forma de tratamento de problemas reais, levando o aluno a uma aprendizagem contextualizada, inserindo-o na sociedade e no mundo do trabalho, como já discutido anteriormente, e como é corroborado pelas seguintes colocações feitas por outros alunos (MIRANDA; GAZIRE, 2013, p. 492).

A potencialidade da contextualização no ensino e aprendizagem consiste em dar significado ao conhecimento científico. Ela pode despertar a interação entre as fronteiras das áreas do saber. Como já lembrado anteriormente, para Japiassu (1976) a interdisciplinaridade pode ser definida como o lançar de pontes entre essas fronteiras.

Desta forma, é preciso repensar a proposta curricular do curso técnico em Alimentos, a fim de incorporar a abordagem das questões ambientais no início do curso para assim os alunos inter-relacionar os conhecimentos da prática educacional à ambiental, além de adotar o contexto local e regional quando se tratar de aspectos ambientais, já que muitos alunos apresentaram desconhecer a realidade do município que eles estão inseridos (MEDEIROS; TABOSA, 2010, p. 193).

Em tempo, pode-se observar que alguns autores apontam a abordagem por meio de temas como possibilidade para fomentar a interação entre as disciplinas no PROEJA.

Cuando se piensa en proyectos didáctico-pedagógico basados en los temas de la experiencia, se necesita revisar qué contenidos son realmente necesarios, cuál debe el grado de complejidad adecuado $y$, con miras a un trabajo interdisciplinar, establecer las relaciones multidisciplinares (COSTA et al, 2015, p. 7).

Neste formato, as categorias de conhecimentos foram elencadas em pacotes temáticos, criando-se a possibilidade da interação de múltiplos conhecimentos de forma interdisciplinar [...] (FURTADO; OLVEIRA, 2013, p. 248).

10 KUENZER, A. Z. Ensino Médio: construindo uma proposta para os que vivem do trabalho. 4. ed. São Paulo: Cortez, 2005. 
Nessa perspectiva, pode-se dizer que a visão presente nesses trabalhos aproxima-se da ideia da interdisciplinaridade por meio de temas transversais. Para Araújo (2014, p. 45) a transversalidade, como o próprio nome indica, se relaciona a

[...] temáticas que atravessam, que perpassam, os diferentes campos de conhecimento, como se estivessem em outra dimensão. Tais temáticas, no entanto, devem estar atreladas à melhoria da sociedade e da humanidade e, por isso, abarcam temas e conflitos vividos pela maioria das pessoas em seu dia a dia.

Essas temáticas são, portanto, contextualizadas e, devem atender às demandas dos alunos, aos interesses das maiorias e não apenas de algumas pessoas. Somente dessa forma, que realmente o PROEJA poderá cumprir com a sua missão: a formação integral de minorias excluídas da sociedade.

A busca pela interdisciplinaridade não é uma atividade fácil no que se refere à escola, afinal depende do empenho de mais de um profissional. Assim, surgem algumas indagações, dentre elas a seguinte: como promover o empenho dos professores dos cursos PROEJA em busca de uma abordagem interdisciplinar nesse programa?

\section{Formação de Professores}

Esta categoria perpassa às demais, afinal, a discussão em torno da formação de professores, com vistas ao trabalho interdisciplinar, permeia as questões discutidas até aqui. Entretanto, devido a sua importância, optou-se em registrá-la separadamente, a fim de organizar a discussão a seu respeito.

Como já destacado anteriormente, o PROEJA possui peculiaridades em relação às demais modalidades de ensino. Assim, os artigos convergem em afirmar que devido ao programa ainda ser recente são poucas as iniciativas de formação inicial e permanente que discutam o ensino e aprendizagem no PROEJA. Todavia, para uma abordagem interdisciplinar no programa, é necessário criar momentos e espaços de reflexão sobre a sua estrutura e as suas especificidades, sobre o que é ser professor no PROEJA. 
Nesse sentido, é imprescindível a reorganização do currículo e dos tempos e espaços de atuação dos professores, a fim de que possam incorporar à sua prática pedagógica, além do domínio técnico da ciência que professam, leituras que contribuam para a apropriação dos princípios fundantes do currículo integrado e para 0 conhecimento tecnológico para situar sua disciplina em um contexto abrangente no curso em que atua (SILVA; SÁ, 2016, p. 386).

Cabe salientar que, devido à demanda de formação permanente voltada ao PROEJA, a partir de 2006, a Secretaria de Educação Profissional e Tecnológica - SETEC convidou instituições da Rede Federal de Educação Profissional, Científica e Tecnológica a apresentarem e ofertar cursos de especialização nessa área. Algumas instituições mantêm a oferta do curso atualmente. Entre os objetivos listados no site do Ministério da Educação e Cultura (MEC), sobre esses cursos, consta o desenvolvimento de currículos integrados de Educação Profissional, com a Educação Básica, na modalidade EJA. Acredita-se que esse pode ser um espaço que contribua, portanto, para um caminhar em direção ao desenvolvimento da interdisciplinaridade no PROEJA. Este é um fato positivo, à medida que possibilita aos educadores interessados em atuar no programa, a discutir e refletir sobre suas vivências e experiências no âmbito do PROEJA.

Todavia, artigos analisados ressaltam que a formação não pode ser apenas esporádica, ou limitar-se a um curso lato sensu. A formação inicial e permanente, de que tratam os trabalhos, pode ser realizadas por meio de grupos de estudos, os quais possibilitem o desenvolvimento de uma práxis pedagógica. Pode-se dizer que se trata da formação de professores reflexivos críticos que, para Imbernón (2011), devem não só ministrar suas aulas, mas, participar ativamente em todos os processos escolares (educativos e formativos). Imbernón (2017) destaca que a formação do professor não é iniciada e nem se limita a aquisição de conhecimentos teóricos das disciplinas acadêmicas. Trata-se de um processo que se dá ao longo da vida profissional e ocorre

[...] através das ações formativas, em distintas modalidades, que o corpo docente vai cursando ao longo de sua vida, mas também, é muito importante e convêm destacar, o contato com os 
companheiros de trabalho, o ambiente de sala de aula e da escola e a interação com os alunos (tanto em uma aprendizagem formal como informal). Desse meu ponto de vista, o contato com os colegas é uma das faces da formação permanente e desenvolvimento profissional que tem mais impacto nos professores. E, claro, em menor grau, mas não menos importante, também o que é fornecido pelo seu entorno, os alunos e a organização da escola (ambiente social, institucional, educativo...). Tudo isso vai constituindo e construindo uma trajetória profissional, um itinerário vital que vai confirmando a maneira de ser, pensar e sentir a educação (IMBERNÓN, 2017, p. 71, tradução nossa).

Trata-se, portanto, de um trabalho cooperativo que possibilite o compartilhamento de experiências e favoreça a interação entre as disciplinas.

\begin{abstract}
Las interacciones sociales entre los docentes con distintas formaciones contribuyen para la toma de conciencia de las medidas adoptadas con miras a mejorar la planificación de acciones futuras. El reconocimiento de las especificidades de la educación de jóvenes y adultos permite al profesor, partiendo de estudios teóricos, repensar y cambiar la práctica. Por lo tanto, los cursos de formación docente deberían contribuir para la interrelación entre la teoría y la práctica, vinculando las acciones de los profesores en la formación inicial y continuada (COSTA et al, 2015, p. 10).
\end{abstract}

É a partir do estabelecimento de espaços e momentos em que os educadores possam refletir sobre sua prática que poderão, a partir do trabalho coletivo, e da interação, elaborar materiais didáticos e metodologias de ensino e aprendizagem, na perspectiva interdisciplinar, isto é, construir um currículo integrado.

Consequentemente, acredita-se que os educadores do PROEJA são capazes de construir interdisciplinarmente materiais diferenciados, voltados aos seus cursos específicos, reconhecendo necessidade da formação técnica, básica e social do profissional, e, por fim, fazendo das diferenças a possibilidade para a criação de uma nova proposta de ensino e de uma aprendizagem significativa para um cidadão crítico e transformador da sociedade (MIRANDA; GAZIRE, 2013, p. 493).

Moura e Henrique (2012, p. 127), ao analisar a formação de professores no âmbito da EJA, afirmam que essa esfera deverá ter identidade própria. 
[...] constituindo-se em um novo objeto de estudo que demandará métodos específicos, material didático específico, adequação dos horários ao grupo a que se destina, formação dos agentes educacionais envolvidos (professores, pedagogos e gestores). Isso implica em clareza teórica, na vontade política e no compromisso ético com a cidadania conscientizada e emancipada dos grupos destinatários (FREIRE, 2005)11 (MOURA; HENRIQUE, 2015, p. 127).

Nessa perspectiva, alguns autores indicam, que a formação do professor para atuar no PROEJA, pode se dar a partir de sua atuação como "pesquisador". Assumiria, assim, o papel de investigar a sua própria prática, buscando materiais e metodologias adequados e contextualizados.

Para que o professor possa atuar, oferecendo aos jovens e adultos
uma educação integral que concilie a formação técnica com a
humana, de qualidade, é preciso que ele atue primeiro como
pesquisador, construindo os instrumentos didáticos mais adequados às
diversas turmas. Assim, ele poderá possibilitar aos estudantes a
formação de trabalhadores-cidadãos capazes de interagir com o
meio e criar alternativas de inserção e permanência no mundo do
trabalho com competência. Esse processo de pesquisa do professor
exige tempo para ler, refletir e construir materiais didáticos
(CAVALCANTE; ALCÂNTARA, 2009, p. 136).

Para Imbernón (2011), o professor ao assumir uma postura de pesquisador amplia suas possibilidades de compreender o processo ensino e aprendizagem e, assim, transcendendo o imediato, o individual e o concreto, possibilitando que seja um melhor professor.

Inclusive, Moura e Henrique (2012) lembram que os cursos de especialização em PROEJA fundamentaram-se, entre outros, no seguinte pressuposto:

\begin{abstract}
A necessidade da formação de um novo profissional que possa atuar na educação profissional técnica de nível médio integrada ao ensino médio na modalidade EJA como docente-pesquisador, gestor educacional de programas e projetos e formulador e executor de políticas públicas (MOURA; HENRIQUE, 2012, p. 120).
\end{abstract}

Cabe destacar, que para o estabelecimento de um ambiente de formação inicial ou permanente, além da inquietação dos professores na

\footnotetext{
11 Referência citada pelo autor do artigo: FREIRE, P. Pedagogia do oprimido. 41 ed. Rio de Janeiro: Paz e terra, 2005.
}

Revista Exitus, Santarém/PA, Vol. 9, Nº 3, p. 395 - 424, JUL/SET 2019. 
busca de uma práxis pedagógica, são necessárias políticas públicas nesse sentido e o apoio de gestores e equipes pedagógicas das instituições que ofertam o programa.

\section{CONCLUSÕES}

Em suma, o presente trabalho buscou descrever os resultados de uma pesquisa bibliográfica qualitativa, na qual foram analisados nove artigos científicos, que versam sobre a interdisciplinaridade no âmbito do PROEJA publicados nos últimos dez anos. Esse reduzido número de publicações que abordam a interdisciplinaridade no programa, não surpreende, pois, conforme Araújo (2014), a interdisciplinaridade ainda não é uma prática constante nos ambientes escolares e nas universidades, inclusive, muitas tent ativas falharam ou foram abandonadas, ao longo do tempo.

Nesse sentido, acredita-se que esse é um campo a ser explorado, experimentado e investigado. São necessárias mais ações e pesquisas, voltadas a entender a potencialidade da perspectiva interdisciplinar no PROEJA, especialmente, no que diz respeito à integração entre as disciplinas da área básica e as da área técnica de cada curso. Evidentemente, que essa não é tarefa fácil, afinal, como já se disse, necessita de trabalho cooperativo de professores de diferentes áreas, além de apoio institucional.

No que diz respeito aos resultados encontrados na pesquisa, mais especificamente, quanto às categorias finais descritas ao longo deste trabalho, uma frase que sintetiza a visão que se tem em relação às concepções e vivências encontradas nestes, seria: A interdisciplinaridade no PROEJA é de suma importância, pois é por meio dela que se pode desenvolver o currículo integrado, por meio da contextualização de materiais e metodologias adequadas, que considerem a realidade dos alunos como, por exemplo, com a utilização de abordagens temáticas, e, para isso, é necessário promover uma formação permanente crítica de professores, com vistas ao desenvolvimento de uma práxis pedagógica.

Dessa forma, é necessário um maior empenho por parte de pesquisadores, professores e gestores em promover a interdisciplinaridade no 
âmbito do PROEJA. É preciso caminhar em direção à superação da fragmentação disciplinar no programa, na verdade, não só no PROEJA, mas em toda Educação Brasileira. A pesquisa pode contribuir para a melhoria desse cenário, em especial no que se refere a investigar as concepções, práticas e metodologias inerentes ao PROEJA. A pesquisa necessita debruçarse sobre a formação dos professores que atuam no programa, valorizando a formação em serviço, que conforme Imbernón (2011) requer real colaboração entre os pares, pois somente transforma a sua prática, quem realmente quer modificá-la.

Acredita-se que a busca pelo interdisciplinar no PROEJA consiste em uma busca pela formação humana integral. Sua missão está além de, simplesmente, entregar ao fim do curso, um diploma de conclusão de nível médio com uma capacitação profissional. O PROEJA pode representar uma melhoria na qualidade de vida dos seus alunos. Deseja-se que sejam capazes de construir conhecimentos de forma crítica, que possam modificar as suas próprias realidades.

\section{REFERÊNCIAS}

ARAÚJO, U.F. Temas transversais, pedagogia de projetos e mudança na educação. São Paulo: Summus. 2014.

BRASIL. Parâmetros Curriculares Nacionais Ensino Médio. Brasília: Ministério da Educação, 2000.

BRASIL. DOCUMENTO BASE PROEJA (Programa Nacional de Integração da Educação Profissional com a Educação Básica na Modalidade de Educação de Jovens e Adultos). Brasilia: Ministério da Educação, Conselho Nacional de Educação, 2007.

BRASIL. Diretrizes Curriculares Nacionais para a Educação Profissional Técnica de Nível Médio. Brasília: Ministério da Educação, Secretaria de Educação Básica, 2012.

BRASIL. Diretrizes Curriculares Nacionais para Educação Básica. Brasília: Ministério da Educação, Secretaria de Educação Básica, 2013. 
CAVALCANTE, I. F; ALCÂNTARA, D.S. Formação de leitores: o ensino de língua portuguesa em turmas de EJA. Revista HOLOS, Natal, v. 2, ano. 25, p. 132-144, 2009.

COSTA, L. S. O., et al. La Formación Docente y la Educación de Jóvenes y Adultos: Análisis de la Práctica Pedagógica para la Enseñanza de Ciencias. Revista Formación Universitaria, La Serena (Chile), v. 8, n. 1, p. 3-12, 2015.

FAZENDA, I. C. Interdisciplinaridade: história, teoria e prática da pesquisa. Campinas: Papirus. 1994.

FAZENDA, I. C (Org.). Interdisciplinaridade: dicionário em construção. 2. Ed. São Paulo: Cortez. 2002.

FREIRE, P. Pedagogia do oprimido. 41 ed. Rio de Janeiro: Paz e terra, 2005.

FURTADO, R. N. O; OLIVEIRA, M. M. M. Construindo um modelo curricular integrado para a Educação de Jovens e Adultos/Formação Inicial e Continuada (EJA/FIC). Revista HOLOS, Natal, v. 5, ano. 29, p. 234-250, 2013.

GIACON, B. M. Coerência. In: FAZENDA, I. C. A. (Org.). Dicionário em construção: Interdisciplinaridade. 2. ed. São Paulo: Cortez, 2002. p. 35-39.

GIL, A. C. Como elaborar projetos de pesquisa. 4. Ed. São Paulo: Atlas. 2002.

IMBERNÓN, F. Formação docente e profissional: formar-se para a mudança e a incerteza. São Paulo: Cortez, 2011.

IMBERNÓN, F. Ser docente en una sociedad compleja: La difícil tarea de enseñar. Barcelona: Graó Editorial, 2017.

JAPIASSU, I. F. Interdisciplinaridade e patologia do saber. Rio de Janeiro: Imago. 1976.

KUENZER, A. Z. Ensino Médio: construindo uma proposta para os que vivem do trabalho. 4. ed. São Paulo: Cortez, 2005.

MEDEIROS, L. C. ; TABOSA, A. F. T. Percepção ambiental dos estudantes do curso Técnico em Aliment os do PROEJA no IFRN - Campus Currais Novos.

Revista HOLOS, Natal, v. 3, ano. 26, p. 178-195, 2010.

MIRANDA, P. R.; GAZIRE, E. S. Interdisciplinaridade no PROEJA: uma proposta possível no caderno temático Saúde e Números. Revista Bolema, Rio Claro, $v$. 27, n. 46, p. 481-496, ago., 2013. 
MORAES, R. Uma tempestade de luz: a compreensão possibilitada pela análise textual discursiva. Ciência \& Educação, Bauru, v.9, n.2, p.191-211, 2003.

MOREIRA, M. A. Pesquisa em ensino: aspectos metodológicos. In: Instituto de Física - UFRGS. Burgos: Universidade de Burgos, 2003. Disponível em:

$<$ http://www.if.ufrgs.br/ moreira/pesquisaemensino.pdf>. Acesso em: 14 out. 2016.

MOURA, D. H.; HENRIQUE, L. S. PROEJA: entre desafios e possibilidades. Revista HOLOS, Natal, v. 2, ano. 28, p. 114-128, 2012.

PIAGET, J. Psychologie et épistémologie. Gonthier, Paris, 1970.

POMBO, O. Interdisciplinaridade e integração dos saberes. Linc em Revista, Rio de Janeiro, v. 1, n. 1, p. 3-15, ago., 2005.

POMBO, O. Epistemologia da Interdisciplinaridade. Ideação, Foz do Iguaçu, v. 10, n. 1, p. 9-40, 1. Sem., 2008.

SÁ JÚNIOR, L. A.; SANTOS, J. M. Experiências de ensino no PROEJA: práticas de leitura e escrita que vão do cordel á filosofia. Revista HOLOS, Natal,v.2, ano. 27, p. 112-120, 2011.

SILVA, J. M. N. ; SÁ, L. T.F. O PROEJA no IFRN-Campus Mossoró por seus estudantes. Revista HOLOS, Natal, v.7, ano. 32, p. 378-387, 2016.

ZEN, E. T.; OLIVEIRA, E. C. O projeto integrador e a centralidade do trabalho para a formação humana no programa de integração da Educação

Profissional com a Educação Básica na modalidade de Educação de Jovens e Adultos (PROEJA) IFES Campus Vitória/ES. Revista HOLOS, Natal, v.2, ano. 30, p. 134-142, 2014.

Recebido em: 16 de abril de 2018. Aprovado em: 28 de setembro de 2018. 